\title{
PROGRESS ON NUMERICAL SIMULATION OF NANOFLUIDS: IMPACT OF AN ISOTHERMAL SPHERICAL PARTITION ON THE MIXED CONVECTION OF NANOFLUIDS WITHIN CUBIC ENCLOSURES
}

\author{
A. BOUTRA ${ }^{1,2, *}$, K. RAGUI ${ }^{1}$, N. LABSI ${ }^{I}$, Y.K. BENKAHLA ${ }^{1}$, R BENNACER ${ }^{2}$ \\ ${ }^{1}$ Laboratory of Transport Phenomena, USTHB, Algiers, Algeria. \\ ${ }^{2}$ Ecole Supérieure des Sciences Appliquées d'Alger, Algerie. \\ ${ }^{3}$ LMT - ENS Cachan - CNRS - Paris Saclay University, 94230 Cachan, France
}

\begin{abstract}
The main objective of our work is to light out the three-dimensional flow of an Ag-water nanofluid within a lid-driven cubical space which equipped with a spherical heater into its center. Due to its crucial role in the characterization of the main transfer within such configurations, impact of some parameters is widely inspected. It consists the Richardson value $(0,05$ to 50$)$, the solid volume fraction $(0 \%$ to $10 \%)$, as well as the heater geometry $(10 \% \leq \mathrm{d} \leq 25 \%)$. To do so, a numerical code based on the Lattice-Boltzmann method, coupled with a finite difference one, is used. The latter has been validated after comparison between the present results and those of the literature. It is to note that the three dimensions D3Q19 model is adopted based on a cubic Lattice, where each pattern of the latter is characterized by nineteen discrete speeds.
\end{abstract}

\section{NOMENCLATURE}

a Coefficient in external forces $(=\mathrm{g} \beta)$

$\mathrm{a}_{\mathrm{ij}} \quad$ Coefficients in Equation (12)

c Cold

$\mathrm{c}_{\mathrm{s}} \quad$ Sound velocity in the Lattice $\left(\mathrm{c}_{\mathrm{s}}=1 / \sqrt{3}\right)$

$\mathrm{C}_{\mathrm{p}} \quad$ Specific heat at constant pressure, $\left(\mathrm{J} \mathrm{kg}^{-1} \mathrm{~K}^{-1}\right)$

f fluid

$\mathrm{f}_{\mathrm{eq}} \quad$ Equilibrium distribution Function

$\mathrm{F}_{\mathrm{ext}} \quad$ External Force

$\mathrm{f}_{\mathrm{i}} \quad$ Distribution Function

h Hot

$\mathrm{k}$ Thermal conductivity, $\left(\mathrm{W} \mathrm{m}^{-1} \mathrm{~K}^{-1}\right)$

$\mathrm{H}_{\mathrm{x}, \mathrm{y}, \mathrm{z}}$ Enclosure dimensions, (m)

$\mathrm{m}_{\mathrm{j}} \quad$ Moments

nf Nanofluid

$\mathrm{Nu} \quad$ Mean Nusselt number

$\operatorname{Pr} \quad$ Prandtl number $(\operatorname{Pr}=v / \alpha)$

s Solid particles

$\mathrm{S}_{\mathrm{j}} \quad$ Relaxation rate

$\mathrm{t}$ Time, (s).

T Temperature, $(\mathrm{K})$

Ri Richardson number,

$\mathrm{u} \quad$ Horizontal velocity component, (m)

$\mathrm{v} \quad$ Vertical velocity component, (m)

w Depth velocity component, (m)

$\mathrm{x}, \mathrm{y}, \mathrm{z}$ Dimensional Cartesian coordinates, (m)

$\mathrm{X}, \mathrm{Y}, \mathrm{Z}$ Dimensionless coordinates, $(\mathrm{X}=\mathrm{x} / \mathrm{H}, \mathrm{Y}=\mathrm{y} / \mathrm{H}, \mathrm{Z}=\mathrm{z} / \mathrm{H})$
Greek letters

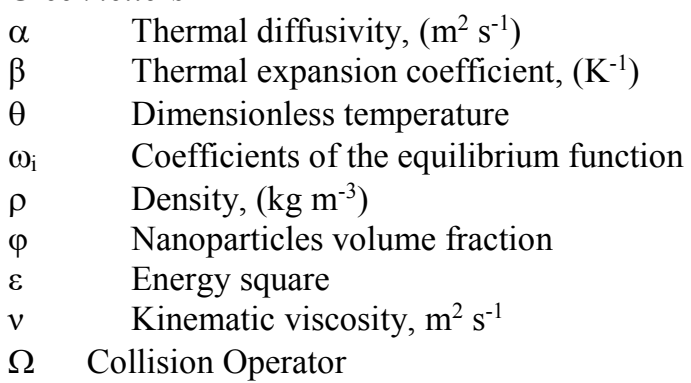

\section{INTRODUCTION}

Through the last years, mixed convection within enclosures was mainly investigated by numerous researchers [1-3]. Such problem in a laminar regime has found its multiple applications in many fields of thermal engineering, such as in electronic device cooling, high performance building insulation, multi shield structures into nuclear reactors, food processing, glass production, solar power collector, to name but a few.

Numerous investigations on lid-driven enclosures, at various basic fluids' flow and temperature gradient' conditions; have been continually published through the literature [4-8]. Recently, the most innovative (and most promising) technique is the injection of nanoscale particles into the base fluid such as the $\mathrm{Ag}, \mathrm{Al}_{2} \mathrm{O}_{3}, \mathrm{Cu}$, $\mathrm{CuO}$ and $\mathrm{TiO}_{2}$, nanoparticles, to enhance the heat transfer rate in engineering systems.

\footnotetext{
* Corresponding author: aeknad@yahoo.fr
} 
In fact, such new concept has been proposed as a smart technique to improve the performance of the thermal transmission of conventional fluids. Thus, the interest presented by the nanofluids has given rise to numerous studies [9-11], which have focused on the determination of their thermophysical properties such as the thermal conductivity, specific heat and the dynamic viscosity and their impact on the flow and heat transfer.

As such our main purpose is to clear up such present technique in $3 \mathrm{D}$ visualization, using a spherical heater as a heat source within a lid-driven cube. The numerical study will be developed using the coupling between Lattice Boltzmann method and finite difference method $[12,15]$.

Noted that the Brownian motion is not taken into consideration in our study since the nanoparticles size is assumed to be greater than $40 \mathrm{~nm}$.

\section{PROBLEM STATEMENT}

The considered model in this paper is shown through Fig.1. Its consists a Tri-dimensional lid-driven cubical enclosure of a height $(\mathrm{H})$ and cold-side walls. The latter; filled with Ag-water nanofluid; contains an isothermal spherical source of diameter (d) which mounted at the middle of the cube. The rest walls of the enclosure are assumed to be insulated.

The thermo-physical properties of the base fluid and the spherical Ag nanoparticles are summarized through Table 1. Constant thermo-physical properties are considered for the nanofluid whilst the density variation, in the buoyancy term, was determined using the Boussinesq approximation, [16].

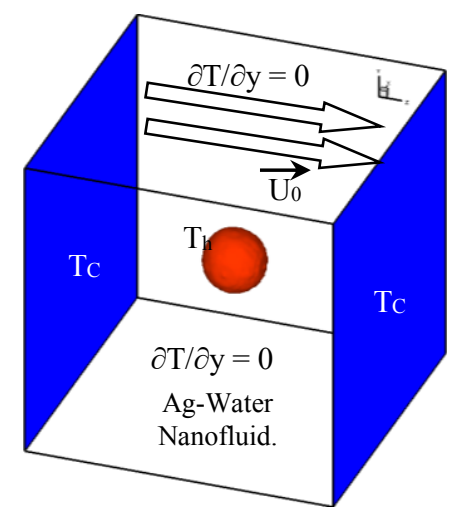

Fig 1 Simulation domain with its boundary conditions

Table 1: Thermophysical properties of the base fluid and the Ag nanoparticles, $\operatorname{Pr}=6.2$.

\begin{tabular}{lcc}
\hline \multicolumn{1}{c}{$\begin{array}{c}\text { Thermophysical } \\
\text { properties }\end{array}$} & $\begin{array}{c}\text { Base fluid } \\
\text { (water) }\end{array}$ & $\mathrm{Ag}$ \\
\hline $\mathrm{C}_{\mathrm{p}}\left(\mathrm{J} \mathrm{kg}^{-1} \mathrm{~K}^{-1}\right)$ & 4179 & 230 \\
$\rho\left(\mathrm{kg} \mathrm{m}^{-3}\right)$ & 997.1 & 10500 \\
$\mathrm{k}\left(\mathrm{W} \mathrm{m}^{-1} \mathrm{~K}^{-1}\right)$ & 0.613 & 418 \\
$\beta(\mathrm{K}) 10^{5}$ & 21 & 1.65 \\
\hline
\end{tabular}

\section{MATHEMATICAL FORMULATION}

The nanofluid density, noted as $\rho_{n f}$, heat capacity ( $\rho$ $\left.C_{p}\right)_{n f}$, thermal expansion coefficient $(\rho \beta)_{n f}$, and thermal diffusivity $\alpha_{n f}$, may be defined respectively, as follows :

$\rho_{\mathrm{nf}}=(1-\varphi) \rho_{\mathrm{f}}+\varphi \rho_{\mathrm{s}}$

$\left(\rho \mathrm{C}_{\mathrm{p}}\right)_{\mathrm{nf}}=(1-\varphi)\left(\rho \mathrm{C}_{\mathrm{p}}\right)_{\mathrm{f}}+\varphi\left(\rho \mathrm{C}_{\mathrm{p}}\right)_{\mathrm{s}}$

$(\rho \beta)_{\mathrm{nf}}=(1-\varphi)(\rho \beta)_{\mathrm{f}}+\varphi(\rho \beta)_{\mathrm{s}}$

$\alpha_{\mathrm{nf}}=\frac{\mathrm{k}_{\mathrm{nf}}}{\left(\rho \mathrm{C}_{\mathrm{p}}\right)_{\mathrm{nf}}}$

For the effective dynamic viscosity $\mu_{n f}$, and the effective thermal conductivity $k_{n f}$, Brinkman [17] and Maxwell-Garnetts models [18] are employed, respectively, as:

$\begin{aligned} \mu_{\mathrm{nf}} & =\frac{\mu_{\mathrm{f}}}{(1-\varphi)^{2.5}} \\ \frac{\mathrm{k}_{\mathrm{nf}}}{\mathrm{k}_{\mathrm{f}}} & =\frac{\left(\mathrm{k}_{\mathrm{s}}+2 \mathrm{k}_{\mathrm{f}}\right)-2 \varphi\left(\mathrm{k}_{\mathrm{f}}-\mathrm{k}_{\mathrm{s}}\right)}{\left(\mathrm{k}_{\mathrm{s}}+2 \mathrm{k}_{\mathrm{f}}\right)+\varphi\left(\mathrm{k}_{\mathrm{f}}-\mathrm{k}_{\mathrm{s}}\right)}\end{aligned}$

The dimensionless conservation equations, describing the transport phenomenon inside the cube, can be written as follows:

$$
\begin{aligned}
& \nabla \overrightarrow{\mathrm{V}}^{\prime}=0 \\
& \frac{\partial \overrightarrow{\mathrm{V}}^{\prime}}{\partial \mathrm{t}}+\left(\overrightarrow{\mathrm{V}}^{\prime} . \vec{\nabla}\right) \overrightarrow{\mathrm{V}}^{\prime}=-\vec{\nabla} \mathrm{P}+\frac{\mu_{\mathrm{nf}}}{\operatorname{Re} \rho_{\mathrm{nf}} \alpha_{\mathrm{f}}} \nabla^{2} \overrightarrow{\mathrm{V}}^{\prime}+\frac{(\rho \beta)_{\mathrm{nf}}}{\rho_{\mathrm{nf}} \beta_{\mathrm{f}}} \operatorname{Ri} \theta \\
& \frac{\partial \theta}{\partial \mathrm{t}}+\left(\overrightarrow{\mathrm{V}}^{\prime} . \vec{\nabla}\right) \theta=\frac{1}{\operatorname{Re} \operatorname{Pr}} \frac{\alpha_{\mathrm{nf}}}{\alpha_{\mathrm{f}}} \nabla^{2} \theta
\end{aligned}
$$

where $\mathrm{V}^{\prime}$ is the velocity component $\mathrm{U}$ in $\mathrm{X}$ direction, $\mathrm{V}$ in $\mathrm{Y}$ direction and $\mathrm{W}$ in the $\mathrm{Z}$ one. $\mathrm{Ri}\left(=\mathrm{Gr} / \mathrm{Re}^{2}\right)$ is the Richardson number, $\operatorname{Pr}\left(=v_{\mathrm{f}} / \alpha_{\mathrm{f}}\right)$ is the Prandtl number.

\section{LATTICE BOLTZMANN APPROACH}

Regarding the Lattice Boltzmann equation for nanofluids, a nineteen-velocity model on a threedimensional lattice, noted as D3Q19, is utilized [19]. For the adopted dynamic model, two successive phases are taken into account; starting with the first one which expresses the propagation of particles from nodes to their neighbors, and continuous with the second one, so-called as the collision, where particles on the same lattice redistribute and relax into their quasi-equilibrium. The particles distribution equation can be expressed as follows:

$$
\frac{\partial \overrightarrow{\mathrm{f}}}{\partial \mathrm{t}}+\overrightarrow{\mathrm{c}} \nabla \overrightarrow{\mathrm{f}}=\left(\frac{\partial \overrightarrow{\mathrm{f}}}{\partial \mathrm{t}}\right)_{\text {scat }}
$$

where $f(x, c, t)$ is the distribution function depending on the particle velocity ( c ) at a location (x) and a time (t). According to Guo et al. [19], the right side term of particles distribution equation displays the diffusion 
process when the new equilibrium distribution is rebuilt after the collision.

Function of the location ( $x$ ) and the time $(\mathrm{t})$, the fluid shape can be defined as particles populations vector, noted as $f_{i}$, where $i=0,1,2, \ldots, 18$. Thus, the discrete distribution equation can be given as:

$$
\mathrm{f}_{\mathrm{i}}\left(\mathrm{x}+\mathrm{c}_{\mathrm{i}} \Delta \mathrm{t}, \mathrm{t}+\Delta \mathrm{t}\right)=\mathrm{f}_{\mathrm{i}}(\mathrm{x}, \mathrm{t})+(\Omega \mathrm{f})_{\mathrm{i}}
$$

where $\left(f_{i}\right)$ is the space vector based on the discrete velocity set and $\Omega$ is the collision operator. Noted that a primary discrete velocity sets will be created then from the set of 18 vectors pointing from the origin to the above neighbors and the zero vector $(0,0,0)$.

The space vector, $f_{i}$, is constructed using the moment of the last. The relationship between two spaces is defined by means of the below equation, when the coefficient $\mathrm{a}_{\mathrm{ij}}$ is calculated using the particle velocity $\mathrm{c}_{\mathrm{i}}$.

$$
\mathrm{m}_{\mathrm{j}}=\sum_{\mathrm{i}} \mathrm{a}_{\mathrm{ij}} \mathrm{f}_{\mathrm{i}}
$$

where the corresponding 19 moments $m_{j}(0,1,2, . ., 18)$ are: the mass density $\left(m_{0}=\rho\right)$, the kinetic energy independent of the density $\left(\mathrm{m}_{1}=\mathrm{e}\right)$, the kinetic energy square independent of the density and kinetic energy $\left(\mathrm{m}_{2}\right.$ $\left.=\varepsilon=\mathrm{e}^{2}\right)$, the momentums $\left(\mathrm{m}_{3 ; 5 ; 7}=\mathrm{j}_{\mathrm{x} ; \mathrm{y} ; \mathrm{z}}\right)$, the energy flux independent of the mass flux $\left(\mathrm{m}_{6 ; 8 ; 10}=\mathrm{q}_{\mathrm{x} ; \mathrm{y} ; \mathrm{z}}\right)$, and the symmetric traceless viscous stress tensor $\quad\left(m_{9}=3 p_{x x}\right.$, $\mathrm{m}_{11}=\mathrm{p}_{\mathrm{ww}}=\mathrm{p}_{\mathrm{yy}}-\mathrm{p}_{\mathrm{zz}}$, with $\mathrm{p}_{\mathrm{xx}}+\mathrm{p}_{\mathrm{yy}}+\mathrm{p}_{\mathrm{zz}}=0, \mathrm{~m}_{13 ; 4 ; 15}=$ $\left.\mathrm{p}_{\mathrm{xy} ; \mathrm{yz} ; z \mathrm{z}}\right)$.

The two vectors of quadratic order, $\mathrm{m}_{10}$ and $\mathrm{m}_{12}$, have the same symmetry as the diagonal part of the traceless tensor $\mathrm{p}_{\mathrm{ij}}$, while the other three vectors of cubic order are parts of a third rank $\mathrm{m}_{16 ; 17 ; 18}$ tensor, with the symmetry of $j_{k} p_{n m}$. The diagonal collision matrix $S_{i j}$ is given as:

$\mathrm{S}_{\mathrm{ij}}=\left(\begin{array}{l}0, \mathrm{~s}_{1}, \mathrm{~s}_{2}, 0, \mathrm{~s}_{4}, 0, \mathrm{~s}_{4}, 0, \mathrm{~s}_{4}, \mathrm{~s}_{9}, \mathrm{~s}_{10}, \\ \mathrm{~s}_{9}, \mathrm{~s}_{10}, \mathrm{~s}_{13}, \mathrm{~s}_{13}, \mathrm{~s}_{13}, \mathrm{~s}_{16}, \mathrm{~s}_{16}, \mathrm{~s}_{16}\end{array}\right)$

Note that relaxations are related to the dynamic viscosity [20].

About the energy equation, and because of the nonexistence of non-linearity, the finite-difference scheme is found more required than the LBE-scheme. The relation between the temperature and flow fields is found to be as far as the force in the y-direction, which arises with the temperature gradient, is introduced. The later is thus, used in the y-velocity calculations, as shown in the advection term in the energy equation cited below:

$$
\frac{\partial \mathrm{T}}{\partial \mathrm{t}}+\overrightarrow{\mathrm{V}} \nabla \mathrm{T}=\mathrm{k} \Delta \mathrm{T}
$$

At the end, it is worth to denote that the mean Nusselt number computed along the side walls is obtained through the following expressions:

$$
\mathrm{Nu}=\left(\frac{\mathrm{k}_{\mathrm{nf}}}{\mathrm{k}_{\mathrm{f}}}\right) \int_{0}^{\mathrm{H}} \int_{0}^{\mathrm{H}}(\partial \mathrm{T} / \partial \mathrm{x})_{\mathrm{X}=0, \text { or } \mathrm{H}} \mathrm{dydz}
$$

where $\mathrm{k}_{\mathrm{nf}}$ and $\mathrm{k}_{\mathrm{f}}$ are the nanofluid and the base fluid thermal diffusivity, respectively.

\section{RESULTS \& DISCUSSION}

The presented results are generated for various dimensionless groups; such Richardson number $(0.05 \leq$ $\mathrm{Ri} \leq 50)$, solid volume fraction $(0 \%$ to $10 \%)$ and the middle-source diameter $(0.10 \mathrm{H} \leq \mathrm{d} \leq 0.25 \mathrm{H})$. Though our investigation, the Prandtl number is fixed at 6.2.

The predicted hydrodynamic and thermal fields' variables will be presented, next, using the Streamlines and temperature Iso-surfaces. The mean transfer rate will also represented in order to supply useful information about the influence of each parameter, quoted above, on heat transfer enhancement.

The performance of the using code via the $3 \mathrm{D}$ mixed convection problem is established by comparing predictions with other numerical results, namely those of Iwatsu and J.M. Hyun [21] and Ouertatani et al. [22]. By taking into account the same hypotheses, Table. 2 demonstrate a comparison of the mean Nusselt number computed inside the Air cube. As we can see, the present results and those of Iwatsu and J.M. Hyun and Ouertatani et al. are found to be in excellent agreement with a maximum discrepancy of about $2 \%$.

Table 2: Average Nusselt number obtained with our computer code and those of references [21,22], $\operatorname{Pr}=0.71$.

\begin{tabular}{ccccc}
\hline Re & Ri & $\begin{array}{c}\text { Iwatsu \& } \\
\text { Hyun [21] }\end{array}$ & $\begin{array}{c}\text { Ouertatani } \\
\text { et al. [22] }\end{array}$ & $\begin{array}{c}\text { Present } \\
\text { Work }\end{array}$ \\
\hline \multirow{3}{*}{100} & $10^{-3}$ & 1.820 & 1.836 & 1.838 \\
& 1 & 1.330 & 1.348 & 1.347 \\
& 10 & 1.080 & 1.092 & 1.094 \\
\hline \multirow{3}{*}{400} & $10^{-3}$ & 3.990 & 3.964 & 3.966 \\
& 1 & 1.500 & 1.528 & 1.537 \\
& 10 & 1.170 & 1.130 & 1.162 \\
\hline \multirow{3}{*}{1000} & $10^{-3}$ & 7.030 & 7.284 & 7.289 \\
& 1 & 1.800 & 1.856 & 1.858 \\
& 10 & 1.370 & 1.143 & 1.140 \\
\hline
\end{tabular}

\section{Convection-mode'impact}

As far as the Richardson number is concerned, Fig. 2 displays the temperature Iso-surfaces (a) side by side with the Streamlines and the Isotherm plots (b) for various flow regimes. Regarding the basic fluid case, (i.e. $\varphi=0$ ), the fluid flow is generated by the translational movement of the horizontal wall as long as the forced mode primes (as for $\mathrm{Ri}=0.01$ ). A cell rotating clockwise occupies the entire space; which come around the obstacle. Near the lower corners of the enclosure, two secondary cells raises reason to the stagnant flow into such spaces.

Besides, and for low values of Richardson, the convection mechanism light out within the cubical space. Such behavior tends to be pure-conduction as long as the Richardson value increases (see for instance $\mathrm{Ri}=10$ ). 
Going far with its impact; the increasing source diameter on the temperature distribution is plotted through the Iso-surfaces as displayed in Fig. 3. At this part, only the forced convection mode will be treated ( $\mathrm{Ri}$ $=0.01$ ).

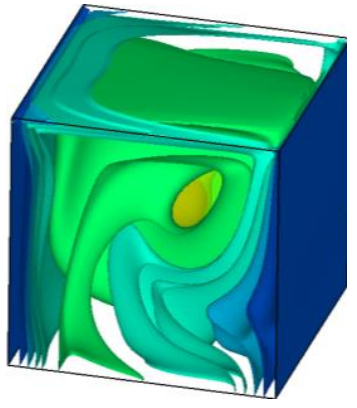

$(\mathrm{Ri}=0.05)$

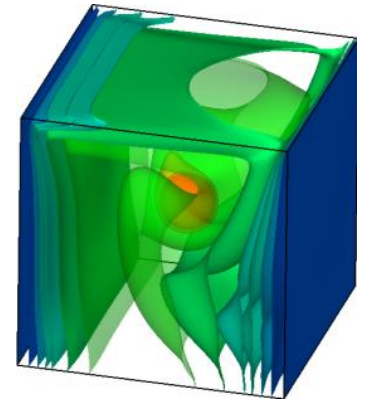

$(\mathrm{Ri}=1)$

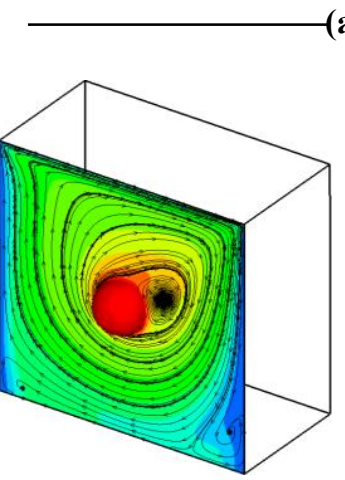

$(\mathrm{Ri}=0.05)$

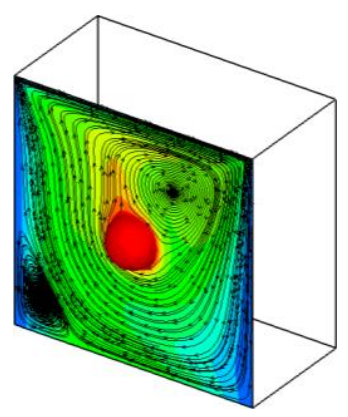

$(\mathrm{Ri}=1)$

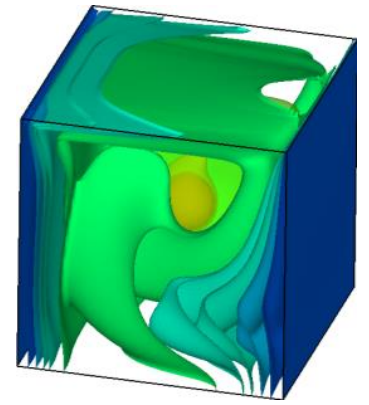

$(\mathrm{Ri}=0.01)$

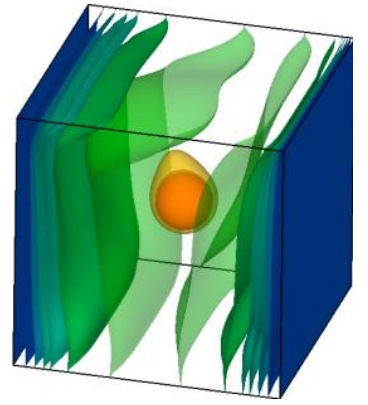

$(\mathrm{Ri}=50)$

a)

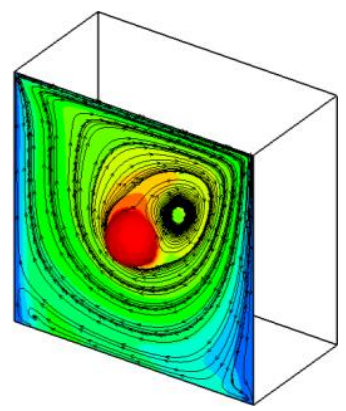

$(\mathrm{Ri}=0.01)$

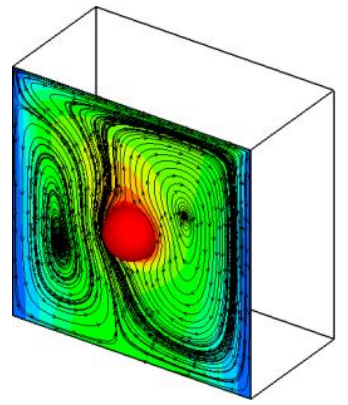

$(\mathrm{Ri}=50)$

(b)

Fig. 2 Temperature Iso-surfaces (a), Streamlines and Isotherm plots (b) of nanofluid for various values of the Richardson number, $d=0.10 \mathrm{H}$ and $\varphi=0$.

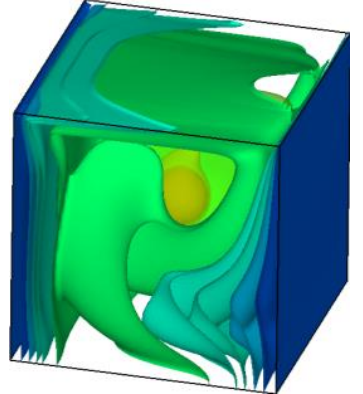

$(d=10 \%)$

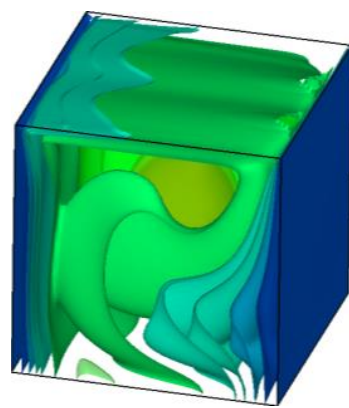

$(d=20 \%)$

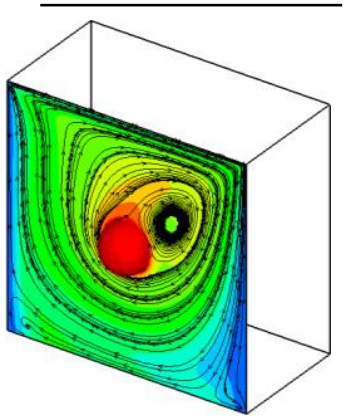

$(\mathrm{d}=10 \%)$

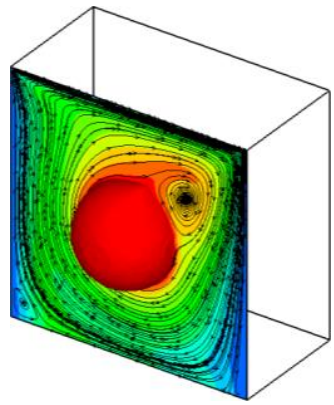

$(d=20 \%)$

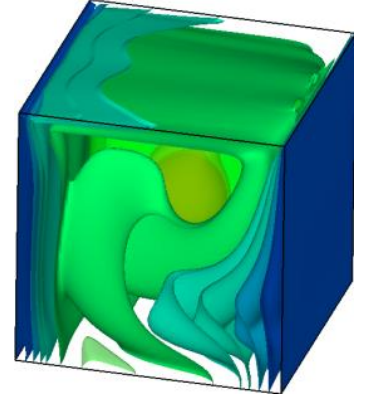

$(d=15 \%)$

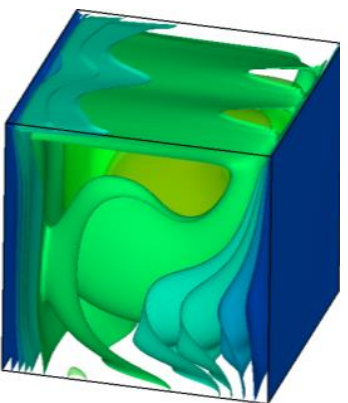

$(d=25 \%)$

(a)

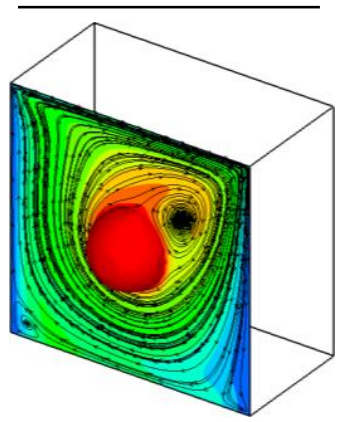

$(\mathrm{d}=15 \%)$

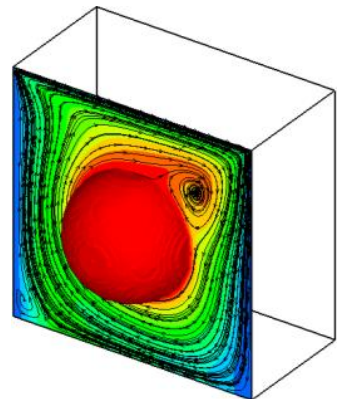

$(d=25 \%)$

(b)
Fig. 3 Temperature Iso-surfaces (a), streamlines and Isotherm plots (b) of the nanofluid for various values of the diametr $d$,

$$
(\mathrm{Ri}=0.01) \text {. }
$$

Gradually, as the width of the heat source increases; the convective fluid flow becomes strong. Consequently, the thermal boundary layer near the active walls of the enclosure gets thin; making the transfer rate very significant. 


\section{Nanoparticles' impact}

The variations of the average Nusselt number with nanoparticles volume fraction for different Richardson number are depicted in Fig. 4. The figure shows that the average Nusselt number increases with the solid volume fraction and decrease with Richardson number (which plotted using the mean Nusselt number). Yes of course, the increase in the source diameter, (i.e. the dimension of the middle sphere) amplifies such developed transfer within the cubical space (see for instance Fig .5).

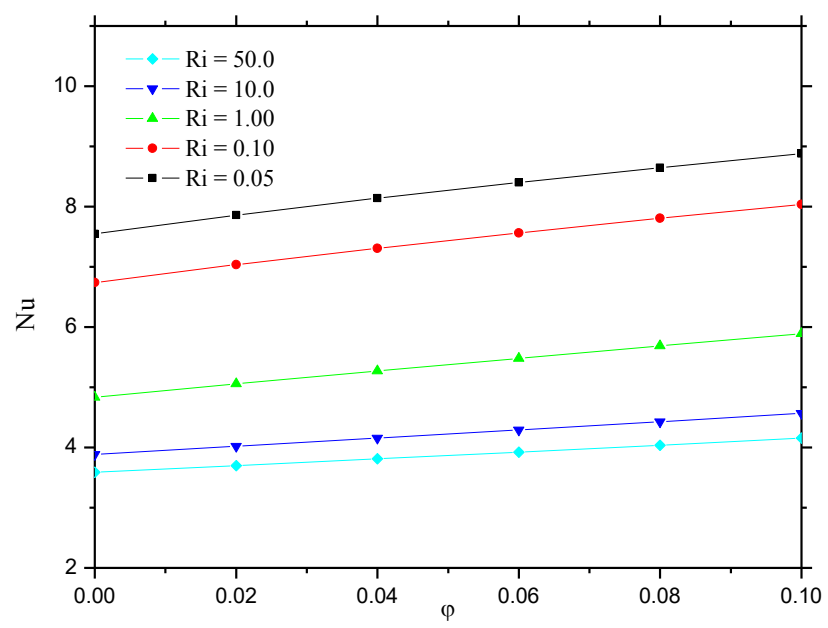

Fig. 4 Mean transfer rate evolution with respect values of Richardson and Ag nanoparticles' volume fractions.

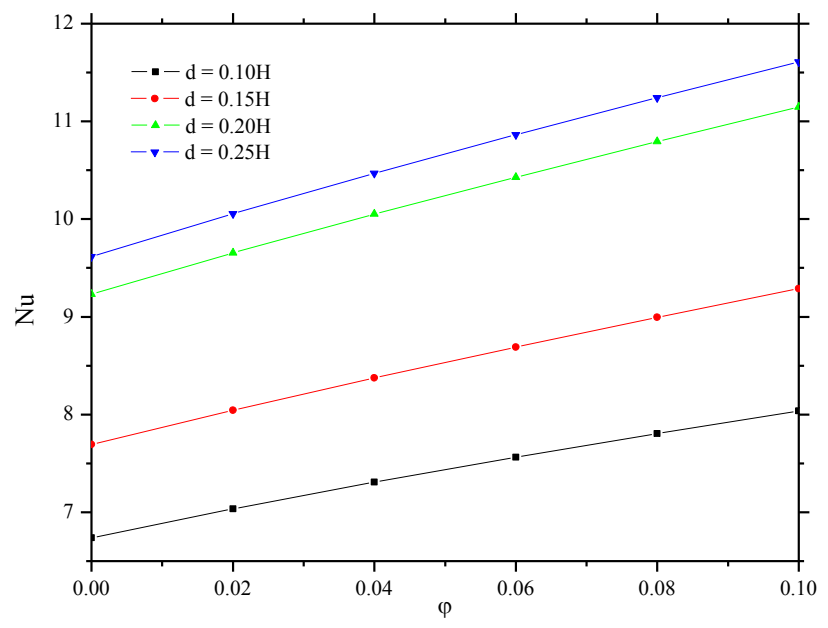

Fig. 5 Mean transfer rate evolution with respect values of the source dimension and the Ag nanoparticles' volume fractions.

\section{CONCLUSION}

Mixed convection phenomenon within a cubical enclosure; including a heated spherical source which located at the center of the space; was investigated through our paper. Taking into account the impact of various pertinent parameters; such as Richardson; the nanoparticles volume fractions; side by side with source dimension; heat transfer is found very significant consequences to the dispersion of solid nanoparticles into the base fluid and increases by increasing the nanoparticles volume fraction. The latter is a decreasing function of the crease Richardson number as the conduction mode primes. Yes of course, the increase in the source dimension amplifies the transfer within such geometry as the surface exchange gets important.

\section{REFERENCES}

[1] A. Boutra, K. Ragui, Y.K. Benkahla, Mechanics \& Industry, 16 (5): 505 (2015).

[2] A. Boutra, K. Ragui, N. Labsi, Y.K. Benkahla, Open Eng. 5, 248-255 (2015).

[3] O. Nasreddine, N.B. Cheikh, Int. J. Thermal Sciences, 48, 1265-1272 (2009).

[4] J.R. Koseff, R.L. Street, J. Fluids Eng. 106: 21-29 (1984).

[5] G. Barakos,E. Mitsoulis, Int. J. Num. Methods Fluids, 18, 695-719 (1994).

[6] B. Calcagni, F. Marsili, M. Paroncini, Appl. Thermal Eng, 25: 2522-2531 (2005).

[7] R.Y Jou, S.C Tzeng, Int. Commun. Heat Mass Transfer, 33: 727-736 (2006).

[8] M.K Moraveji, M. Darabi, S.M.H. Haddad, R. Davarnejad, Int Commun.Heat Mass Transfer, 38: 1291-1295 (2011).

[9] J. Ravnik, L. Škerget, M. Hribersek, Engineering Analysis with Boundary Elements, 34(12), 10181030 (2010).

[10] K. Khanafer, K. Vafai, International Journal of Heat and Mass Transfer, 54(19): 4410-4428 (2011).

[11] E.B. Ögut, Int.J. Thermal Sciences, 48(11): 20632073 (2009).

[12] A. Boutra, K. Ragui, N. Labsi,R. Bennacer, Y.K. Benkahla, Arabian Journal for Science and Engineering, 41: 1969-1980 (2016).

[13] A. Boutra, K. Ragui, R. Bennacer, Y.K. Benkahla, Eur. phys. j. appl. Phys. 74: 24612 (2016).

[14] A. Boutra, K. Ragui, R. Bennacer, Y.K. Benkahla, Energy Procedia, 139: 217-223 (2017).

[15] A. Boutra, K. Ragui, N. Labsi,R. Bennacer, Y.K. Benkahla, Energy Procedia, 139, 173-179 (2017).

[16] A. Bejan, John Wiley \& Sons, Inc., Hoboken, New jersey, USA (2004).

[17] H.C. Brinkman, J. Chem. Physics, 20: 571-581 (1952).

[18] J.C. Maxwell, Oxford University Press, Cambridge, U K, 54 (1873).

[19] D. d'Humières, AIAA Progress in astronautics and aeronautics, 159: 450-458 (1992).

[20] K. Fallah, M. Khayat, M.H. Borghei, A. Ghaderi, E. Fattahi, J. Non-Newt. Fluid Mech, 177, 01-14 (2012).

[21] R. Iwatsu, J.M. Hyun, Int. J. Heat Mass Transfer, 38, 3319-3328 (1995).

[22] N. Ouertatani, N.B. Cheikh, B.B. Beya, T. Lili, A. Campo, Int. Journal of Thermal Sciences, 48(7): 1265-1272 (2009). 